\title{
Determinants of Women Participation on Watershed Management in Gibe Sub- Catchment of Nono Benja District Jimma Zone, Ethiopia
}

\author{
Gemechu Fufa Arfasa (M.Sc.) ${ }^{1^{*}} \quad$ Alemayehu Regassa (PHD) ${ }^{2} \quad$ Bekele Tona (M.Sc) $^{3}$ \\ Jimma University, PO box 307, Jimma, Ethiopia
}

\begin{abstract}
Watersheds, especially in the developing world, are increasingly being managed for poverty alleviation as well as for environmental conservation. In Ethiopia, watershed management.Program started in 1970. However, it achieved limited success due to its failure in addressing the problems of local people. Women's knowledge and role in watershedmanagement is largely unrecognized, especially at catchment level.The objective of this studyis to identify the determinants of women participation on watershed management, in Nono Benja district ofJimma Zone. Two stage sampling techniques were used to select sample respondents. In the first stage, from 19 kebele of the district, 6 kebeles were selected by simple random sampling, In the second stage 248 respondents were selected based on probability proportional to the size of population. The necessary data were generated both from primary and secondary sources to answer the research question. Hence, field observation, household survey, key informant interview and focus group discussions were the principal means of generating primary sources of data while secondary data were obtained from reviewing various governmental documents and reports,books and Academic research papers Econometric Model were employed for analyzing data.SPSS version 20 and STATA version 13 software were used for data analysis. The results of the binary logit model indicated that, age, education, training, credit were positively and significantly related to the probability of women participation in watershed management while off farm income was negatively and significantly related to the probability of women participation. Thus, there is need for policies aiming at enhancing women's participation in watershed management by promoting training, providing extension services, off farm income as well as facilitating access to credit services. Policy and development emphasis on these factors would lead to greater participation in Nono Benja watershed development programme
\end{abstract}

Keywords: Women, Logit, Watershed, Socio-Economic, Demographic, Intuitional Factor

DOI: $10.7176 / \mathrm{JRDM} / 80-02$

Publication date: November $30^{\text {th }} 2021$

\section{INTRODUCTION}

1.1 Background of the Study

Watershed, especially in the developing world has increasingly been managed and developed for poverty alleviation and environmental conservation. Watershed is a unit of area covers all the land which contributes runoff to a common point or outlet and surrounded by a ridge line". Technically, a watershed is the divide separating one drainage area from another (Chow, 1964). A watershed or catchment or basin or drainage area refers to any topographically delineated area that can collect water and is drained by river system with an outlet (brooks, et al., 1981). The history of watershed management was dating back to 5000 years old, since agriculture began (Wani and Garg, 2016). Human beings live in a watershed to meet their needs, and they have been manipulating water and slopes in order to benefit cultivation, control floods and drought(Tennyson, 2012).Watershed is not simply the hydrological unit but also a socio-political-ecological entity which plays decisive role in determining the socio-economic security and it helps to support the livelihood of rural community (Worku and Tripathi, 2015).

Government of Ethiopia have initiated watershed development since 1970's and 1980's respectively and increasingly been managed and developed for poverty alleviation and environmental conservation (Chimdesa, 2016).In Ethiopia 85 percent of the population are directly dependent on the agricultural economy. Watershed resource degradation is a serious problem in the Ethiopian which threatening agricultural development and rural livelihood. Since the economy of the country is agrarian in nature, the decline in agricultural productivity adversely affects the economic growth of the country. However, the productivity of that economy is being seriously eroded by unsustainable land management practices, both in areas of food crops and in grazing lands (FAO, 2016). The present Governments have been recognized that protection of watersheds cannot be achieved without the willing participation of local people and taking lessons from the past shortcomings and it has been initiated community based watershed management (Habtamu, 2011). At socio-economic level a watershed includes people, their farming system and interactions with their land resources, coping strategies, social, economic and cultural aspects (Adane, 2010). Watershed Management is the management of land and other resources on a watershed to achieve well-defined environmental, social, and economic goals. 
Unique to the concept of watershed management is recognition of the relationship between land use, soil loss and productivity, water quantity and quality, wildlife populations and habitat, social factors, and economic factors. Upstream and downstream land areas and entities are linked on a watershed through the hydrologic cycle (Ababa, 2014).Watershed is not simply the hydrological unit but also socio-political-ecological entity which plays crucial role in determining food, social, and economical security and provides life support services to rural people. It is the people oriented supporting process designed to reach the objectives of watershed management. In this concept is the recognition of the ecological interrelationships among land use, soil and water, as well as the, social and economic linkages between upland and downstream areas. Watershed management balances the three dimensions of sustainable development: ecological, economic and social in a watershed context (Wani and Garg, 2016).

The concept of watershed management has internationally gained significance following the United Nations Conference on Environment and Development in 1992 in Rio de Janeiro (also known as the Earth Summit) (Förch and Schütt 1992). Watershed management implies the wise use of natural resources like land, water and biomass in a watershed to obtain optimum production with minimum disturbance to the environment (Habtamu, 2011). Watershed management as a measure of development implies that the resources within a defined watershed should be utilized for the benefit of the local population and in harmony with the environment (Samani and Arayesh, 2015). Managing a watershed involves not only individual plots, but also common property resources like forests, springs, gullies, roads and footpaths, and vegetation along streams and rivers (Swallow et al., 2001).

Watershed degradation, in turn, leads to accelerated ecological degeneration, reduced economic opportunities and increased social problems (Berry, 2016). Historical evidences indicate that women had been participating in their political, social, and economic aspect of their country, however, their role in development in general and economy in particular had been challenged and well not recognized. As it is the case in other countries, Ethiopian women are the half portion of the society and they face economic, social, and political problems. They have been neglected from taking power in their own country regardless of their own knowledge and experience of protecting the other half of the population. Women themselves have a problem of feeling inferiority. Inferiority assumption of women is not only the main factor which declines their participation in the life of their family, but also hinders their role in economic development. The discriminatory political, economic and social rules and regulations prevailing in Ethiopia have barred women from enjoying the profits of their labor and economic development (Megersa,2006)

Peoples' participation has been at the centre-stage of the resource conservation and rural development efforts in the developing countries. The use of a gender-sensitive approach to watershed management ensures that both women's and men's unique needs, priorities, and knowledge are incorporated into management plans and policies. Specifically, a gender equity approach can: Increase men's and women's participation in decisionmaking processes related to watershed management; Promote more equitable access to, control over, and distribution of natural resources among social groups; Ensure that watershed management interventions do not adversely affect one social group more than another (Jackie Siles, 2003).

Women make essential contributions to agriculture and rural economic activities in all developing countries. Their roles vary considerably among and within regions and are changing rapidly in many parts of the world where economic and social forces are transforming the agriculture sector(Bagdi, 2012). Watershed resources degradation like deforestation and soil erosion require women to spend more time each day gathering wood and fetching water for their livelihood. In other words, women's role is affected by limited resources which roots from the cultural way of allocating land and other resources (Mukwaya, 2010).

Upper part of Gibe Basin (Nono Benja district) represents ecological fragility, poor resource conditions, high risk of farming situation. It is a typical watershed representing reserve forests, private and common property land uses and severe soil erosion problems. Most the research done related to watershed management in gibe basin focus on physical and biological conservation measure and its impact. This is common in Ethiopia, but there is no research work on women participation in watershed management. Therefore, Women are key players as managers and direct actors in managing natural resources in the watershed and addressing the household food security. How often, they have passive role in watershed management. because of their low educational levels, social customs, and economic dependence. there are number of factors related to socio-economic, demographic and institutional factors on watershed management and women participation. If we are not able to achieve this goal, at least we can understand the gaps behind their participation.

In Nono Benja district there is no equal participation of women and men in watershed management and formal watershed management is male dominated. To researcher's knowledge,investigate determinants of women participation in watershed management in study areas, was not studied by other researchers. Yet, factors affecting women participation in watershed management have not been closely examined in the area and often poorly understood. This study, therefore, attempted to investigate factors affecting women participation on watershed management in Nono Benja district. 


\subsection{Objectives}

(i) To identify the determinants of women participation on watershed management in the study area.

\section{METHODOLOGY}

This chapter deals with description of the study area, data types and method of data collection, sampling procedures, method of data analysis (descriptive statistics, econometric analysis and definition of variables and research hypothesis (including the dependent and independent variables).

\subsection{Description of the Study Area}

This section includes description of the study area's location, population characteristics, climate and soils and economic activities as they relate to the study topic.

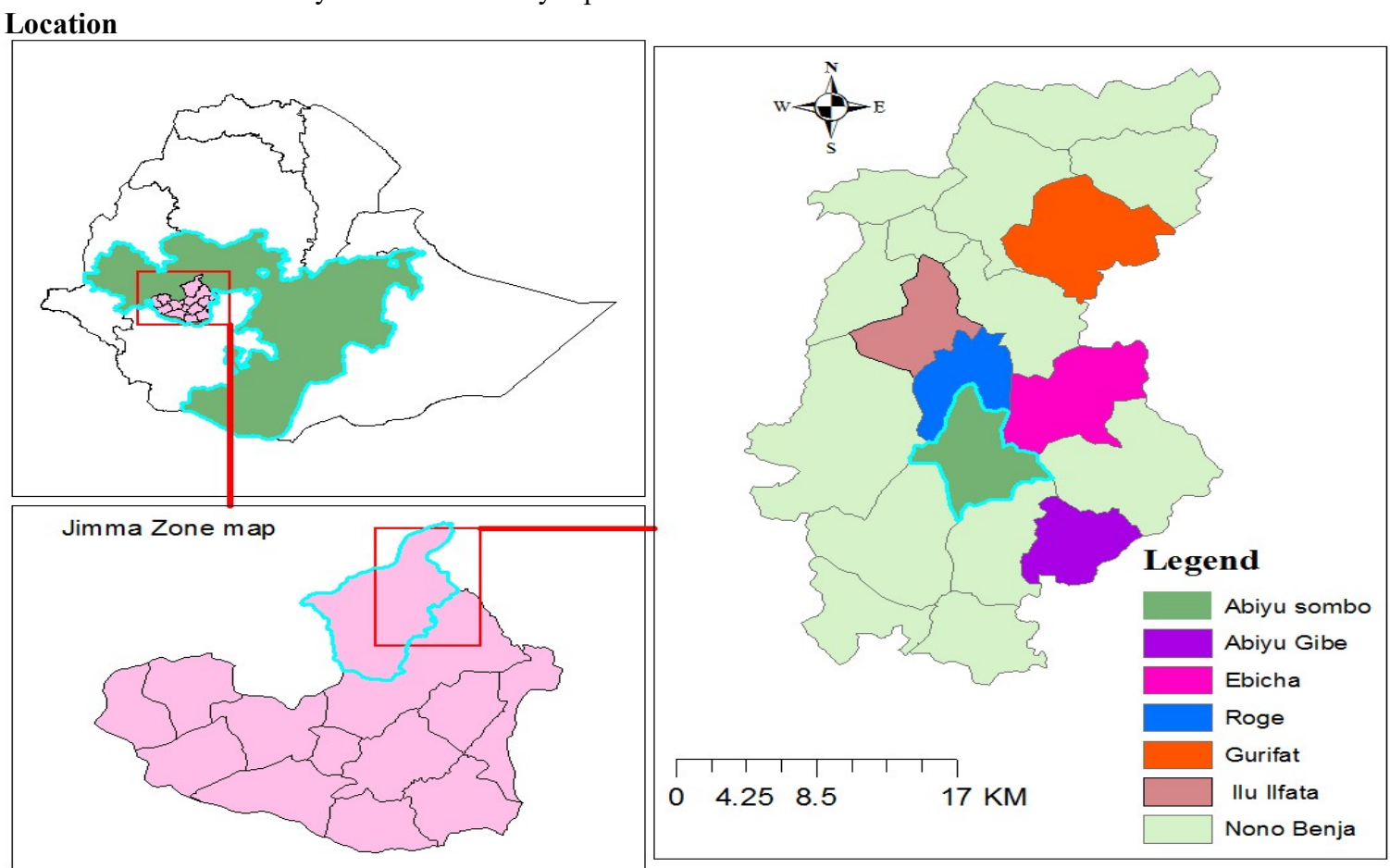

Figure 1 Location of the study area, Nono Benja. (Source: Ethio map).

Nono Benja watershed, is situated in Gibe sub-catchment of Jimma zone, Oromia region, in south west Ethiopia. Watershed management activities in the district start in 1998 E.C by the regional government plan, Watershed in the district covers area $124 \mathrm{~km}^{2}$.It is a typical watershed representing reserve forests, private and common property land uses and severe soil erosion problems. The watershed drains into Gibe river which is a tributary of major system of Gibe Basin i.e. the river Gibe.

\subsection{Sources of Data, Sampling Techniques and Method of Data collection}

\subsubsection{Sources of Data}

The data for this study was generated from both primary and secondary sources of data focusing on both qualitative and quantitative natures.

A. Primary Sources: Primary data were collected about the whole situations of watershed management (socio-economic, demographic and institutional characteristics of the households) from the sample farmer's by semi- structured questionnaire. The questionnaire was being pre-tested before a survey in the area for all necessary adjustments before it was administered in the field. The questionnaires contain both open ended and closed ended questions. Closed ended questions are easier to analyze since they are in an immediate usable form, easy to administer because each item is followed by alternative answers and are economical in terms of time and money. Open-ended questions can stimulate a person to think about his feelings or motives and to express what to be considered being most important.

To complement the questionnaire, opinion leaders (key informants) were interviewed using interview guide. These were women leaders, gender officer, community development officers, agricultural experts, water and environment officers and innovation platform leaders to gain a detailed insight into factors affecting women participation in watershed management. Furthermore, an on-farm observation guide was used to capture 
activities done by women in watershed management, their limitation and strategies to enhance their participation. on-farm observation guide was conducted on watershed management activities and women participation.

B. Secondary Sources: Secondary data collection is a crucial component of any research study. Secondary data sources are usually used to enhance the accuracy, validity, and reliability of research findings. In this study, the secondary data collection exercise was a lengthy process that started with an extensive literature review of published books, journals, and other reports. The secondary sources of information including, research journals and articles, different agricultural development office reports, and document reviewed at different levels of government organizations. The criteria for selecting the documents was, (a) peer reviewed papers published in international journals with priority given to recent papers from the year 2012 and (b) book publications on women's involvement or participation in watershed management.

\subsubsection{Sampling Techniques}

Two stage sampling techniques were used for this study. From the study area (Nono Benja district) six kebeles where selected by simple random sampling. From the six kebeles sample house hold were selected probability proportion to the size of their population. Sample size was determined by Cochran (1977) formula (equation 1). Accordingly, 248 respondents were selected for interview.

$n_{o}=\frac{(\mathrm{p})(\mathrm{q}) * \mathrm{z}^{2}}{\mathrm{~d}^{2}} \quad n_{1=} \frac{n_{o}}{1+\frac{n_{o}}{\mathrm{~N}}}$

Where, $\mathrm{n}_{\mathrm{o}}=$ the desired sample size when the population is greater than 10,000

$\mathrm{n}_{1}=$ the desired sample size when the population is less than 10,000

$z=95 \%$ confidence limit i.e. 1.96

$\mathrm{P}=0.2$ (population proportion to be included in the sample i.e. $20 \%$ )

$\mathrm{q}=1-0.1$ i.e. 0.8

$\mathrm{N}=$ total number of population

$\mathrm{d}=$ margin of error or degree of accuracy (i.e. 0.05 )

Accordingly:

$n_{o}=\frac{(0.2)(0.9) *(1.96)^{2}}{(0.05)^{2}} n_{1=} \frac{0.34574}{1+\frac{0.34574}{2400}}$

$n_{o}=\frac{0.09 * 3.8416}{0.0025}=0.34574$

$$
\begin{array}{r}
n_{1}=\frac{0.18 * 3.8416}{0.0025}=276.59 \\
n 1=\frac{276.59}{1.115}=248
\end{array}
$$

Sample of house hold from kebele was selected as $: \frac{N 1 * \mathbf{n}}{N}-\frac{355 * 248}{2400}-37$ accordingly sample from six kebele was selected.

\subsection{Method of Data Analysis}

Econometric model were used for analyzing data.

\subsubsection{Econometric model}

The binary logit model was used to estimate the probability of women participation on watershed management. In other words, it is used to analyze the determinants of women participation on watershed management i.e. $\operatorname{Pr}\lceil y i=1 \mid x\rceil$ where the model is transformed into the odds as follows (Long, 1997).

$\frac{p(\mathrm{yi}=1 \mid \mathrm{x})}{P(\mathrm{yi}=0 \mid \mathrm{x})}=\frac{\operatorname{pr}(y i=1 \mid x)}{1-\operatorname{pr}(y i=1 \mid x)}$

The odds indicate to what level women was participated on watershed management $(y=1)$ relative to those who did not participate $(\mathrm{y}=0)$. The log of the odds specified in Eq. 3 below suggests that it is linear in the logit.

$\ln \left\lceil\frac{p(y i=1 \mid x)}{1-p(y i=1 \mid x)}\right\rceil=x \beta i$

which is equivalent to the logit model derived as:

$p(y i=1 \mid x)=\frac{\exp (x \beta i)}{1+\exp (x \beta i)}$

where $\mathrm{P}$ denotes the probability that the $\mathrm{i}^{\text {th }}$ women's participate on watershed management, $\mathrm{x}_{\mathrm{i}}$ captures socio- 
economic factors that affect women's participation on watershed management, while $\beta_{\mathrm{i}}$ is a parameter to be estimated.

A binary logit model is useful for investigating the probability of women participation on watershed management since dependent variable is logistically distributed. The dependent variable (y) is the logarithm of the odds in participation, and the parameters are interpreted as derivatives of this logarithm with respect to the independent variables. The estimated coefficients can then be used to predict the participation. In the logit model, like in any nonlinear regression model, the parameters are not necessarily the marginal effects (Greene 2000; Kennedy, 2001), but represent changes in the natural log of odds ratio for a unit change in the explanatory variables.

\subsubsection{Test of multicollinearity problem}

Before fitting the model, it is necessary to carry out multicollinearity test because of the fact that multicollinearity may cause lack of significance of individual independent variables, while the overall model may be strongly significant (Monteshwe, 2006). It may also result in wrong signs and magnitudes of regression coefficient estimates and consequently in incorrect conclusions about relationships between independent variables.

Different methods are often suggested to detect multicoliniarity problem among them, Variance Inflation Factor (VIF) technique was employed to detect mulicoliniarity in continuous explanatory variable. According to Gujarati (2003), VIF (Xi) can be defined as:

$V I F(X i)-\frac{1}{\left(1-R i^{2}\right)}$

Where, $\mathrm{Ri}^{2}$ is the square of multiple correlation coefficients that results when one explanatory variable (Xi) is regressed against all other explanatory variables. The larger the value of VIF is the more troublesome or collinear the variable $\mathrm{Xi}$ is. As a rule of thumb, if the value of VIF is 10 and above, the variables are said to be collinear.

Contingency coefficients will also be calculated to detect the degree of association among the discrete dummy variables. Contingency coefficient is the Chi-square based measure of association. The contingency coefficient (C) will be computed as follow:

$C=\sqrt{\frac{X^{2}}{n+X^{2}}}$

Where; $\mathrm{C}$ is Contingency Coefficient, $\chi 2$, is chi-square random variable and $\mathrm{n}$ is total sample number. A Contingency Coefficient value of 0.75 or more indicates a stronger association between the discrete explanatory variables.

\subsection{Variables Definition and Working Hypotheses}

In this study factors affecting participation of women' in watershed management, the main task is exploring which factors potentially influence and how (the direction of the relationship)these factors are related with the dependent variables.

\section{Dependent Variables}

Women participation on watershed management (PWWM): It was a dummy dependent variable that measures women participation in watershed management. It takes a value of 1 , if a given woman participates in watershed management and 0 , otherwise.

\section{Independent Variables}

After the analytical procedures clearly outlined, it was necessary to identify the potential explanatory variables that have potential influence on women participation in watershed management. The major criterion for the selection of independent variables (explanatory variables) was evidenced from past research, as well as from literature related to the study. Those variables were hypothesized to have positive and negative relationship with the dependent variable. These variables include demographic, socio-economic, and institutional factors.

Age (AGE) of household: It is continuous variable measured in number of the years. It was hypothesized that age of the household might have a positive effect on participation in watershed management. This is because older farmers may might have more experience than younger farmers on watershed management.

Education level(EDUCLVL)of household: It is a continuous variables and defined as the total number of school of households in years. Education is expected to influence positively as it leads to greater awareness about the benefits of watershed management. This is because educated women have more knowledge on watershed management than the others.

Family size (FMSZ): It is a continuous variable and defined as the total number of family members in the households measured in number. The family size (FAMILYSI) is expected to be positively related to participation, as larger families might not face the constraint of labour supply.

Farming Experience (FARMEXP): This is a continuous variable and defined as the total number of experience 
measured in years. It hypothesized that farming experience have positive effect on participation of women in watershed management. This is because, itfacilitate the participation decision as well as with the level of participation.

Off-farm income (OFFINCOME): It is a dummy variable that takes 1 if a farmer participates in off farm activities and 0 , otherwise. Off farm income comprises all incomes generated from off-farm activities. off-farm income generating activity might prevent farmers from participation in watershed management. The off farm income (OFFINCOME) is expected to have a negative sign as more the time farmers spend on off-farm jobs, lesser the time they get for watershed activities.

Total size of farm land(LANDSIZE): Farm land, is a continuous variable measured in the size of the farm, in hectares. Farm land is also expected to influence the participation positively, as those operating on larger farms tend to have greater expected benefits from watershed management programme.

Extension Contact on watershed management (EXTCON): It is a dummy variable which take value 1 if farmer get extension contact and 0 , otherwise. It was hypothesized that extension contact expected to influence participation positively as it helps create awareness and build rapport and It is because farmers who got extension contact had more advisory services on watershed management than the others.

Training(TRAINING): It is a dummy variable that takes value 1 if a farmer has access to training on watershed management and 0, otherwise. Farmers may have different sources for training on watershed management that increase their awareness about watershed management. Hence, training is expected to motivate the farmers for greater participation on watershed management and the expected sign is positive.

Credit (CREDIT): It is a dummy variable that takes value 1 if a farmer get credit and 0, otherwise. Credit services can relax farmers' financial constraints and, in some cases, is tied to a particular watershed management intervention and it was hypothesized to influence farmer's participation positively. Table 1 Modeled explanatory variables, units of measurement and expected sign

\begin{tabular}{|c|c|c|c|c|}
\hline No & Variable Code & $\begin{array}{l}\text { Variable } \\
\text { Type }\end{array}$ & Description \& measurement of variables & $\begin{array}{l}\text { Expected } \\
\text { sign }\end{array}$ \\
\hline 1 & $\mathrm{AGE}$ & Continuous & Age of respondent in years & + \\
\hline 2 & EDCTNLVL & Continuous & Years of schooling of the household & + \\
\hline 3 & FMLYSIZE & Continuous & Number of people in the household & + \\
\hline 4 & FARMEXP & Continuous & The total farming experience in year & + \\
\hline 5 & OFF INCOME & Dummy & $\begin{array}{l}\text { Whether a farmer engaged in off-farm } \\
\text { employment; } 1 \text { if a farmer has off-farm } \\
\text { employment and } 0 \text { otherwise. }\end{array}$ & - \\
\hline 6 & LNDSIZE & Continuous & The size of the farm, in hectares. & + \\
\hline 7 & CREDIT & Dummy & Utilization of credit ( 1 , if yes; 0, No) & + \\
\hline 8 & EXTCON & Dummy & $\begin{array}{l}\text { Contact with extension agents } \\
(1, \text { if yes; } 0, \text { No) }\end{array}$ & + \\
\hline 9 & TRAINING & Dummy & $\begin{array}{l}\text { Whether training about watershed management } \\
\text { received by the farmer; } 1 \text { if a farmer got training } \\
\text { and } 0 \text { otherwise }\end{array}$ & + \\
\hline
\end{tabular}

Source: own computation (2017)

\section{RESULTS AND DISCUSSIONS}

\subsection{Econometric Analysis Results}

In this sub-chapter, multicollinearity test and factors that determine participation of women in watershed management are discussed.

3.2.1 Multicollinearity test

The independent variables were tested for the presence of multicollinearity before running econometric model. As it is indicated that, the values of VIF for continuous variables were lowwhich revealed the absence of severe multicollinearity problem among potential explanatory variables (Appendix 1). Moreover, the values for Contingency Coefficient (CC) for the dummyvariables were less than 0.75 which are obviously the indicators for the absence of severe multicollinearity (Appendix 2).

3.2.2. Determinants of women participation on watershed management

Potential explanatory variables that were expected to influence the women to participate in watershed management were estimated by the help of the maximum likelihood method. Among the 9 hypothesized explanatory variables, only 5 variables were found statistically significant in influencing the women to participate in watershed management. The results of the binary logit model are presented in Table 7 . As it is indicated, age (AGE), education (EDULVL), training (TRAIN) and credit (CREDIT) were positively and 
significantly related to the probability of participation in watershed management while off farm income (INCOME) was negatively and significantly related to the probability of women participation on watershed management. The effects of each explanatory variable on the dependent variable are interpreted as follow:

Table 2. Analysis of determinants using Binary Logistic model

\begin{tabular}{llllll}
\hline PRTCPN & Coeff. & Std. Err. & $\mathrm{P}>\mathrm{Z}$ & {$[95 \%$ Conf. } & Interval] \\
AGE & $.5612 * *$ & 0.2410 & 0.05 & 1.0437 & 2.0055 \\
EDUC & $.5292 * *$ & 0.2690 & 0.04 & 1.0740 & 2.1499 \\
FMLYSZ & -.0443 & 0.1748 & 0.359 & 0.5425 & 1.2480 \\
EXTON & .0177 & 0.1454 & 0.561 & 0.8306 & 1.4073 \\
TRAININ & $.8446 * * *$ & 0.6615 & 0.005 & 1.2812 & 4.0177 \\
CREDIT & $.2301 * *$ & 0.5368 & 0.04 & 0.9387 & 3.1757 \\
INCOME & $-.2355 * * *$ & 0.8750 & 0.001 & 1.5330 & 5.1781 \\
LANSZ & 1.0228 & 0.6403 & 0.125 & 1.5340 & 4.5065 \\
FARM & 0.7747 & 0.2165 & 0.315 & 0.4479 & 1.3397 \\
cons & 0.1368 & 0.1452 & 0.051 & 01708 & 1.0957 \\
\hline
\end{tabular}

Logistic regression Number of obs $=248$

$\operatorname{LR} \operatorname{chi}^{2}(11)=95.59$

Prob $>$ chi $^{2}=0.0000$

$$
\text { Log likelihood }=-141.13 \text { Pseudo } \mathrm{R}^{2}=0.558
$$

** and *** represent, $5 \%$ and $1 \%$ significance level respectively.

Source: Model output (2017)

Age(AGE):Age of the respondents had a positive and significant influence on the participationof women in watershed management at $5 \%$ probability level as expected. The coefficient of age is 0.56 which implies that when the age of household increase by one year, the odd ratio in favor of participating in watershed management increase by $0.56 \%$, keeping othervariables constant (Table 7). This is due to the fact that older farmers might accumulate more knowledge than younger farmers that may help them to make decisions in the watershed management activities. This result is in line with the finding of Amsalu and De Graaff (2014) study determinants of adoption watershed management in an Ethiopian high land watershed found that, age, influence women participation positively and significantly in watershed management.

Education level (EDUCLVL): Education has been hypothesized to have a positive relationship with women participation in watershed management. The model output also reveals that education is positively and significantly related to participation at $5 \%$ probability level as expected. The coefficient of education is 0.53 which implies that for a unit increase in level of education, the odd ratio in favor of participating in watershed management increase by $0.53 \%$, keeping other variables constant (Table 7). This is because farmers that had a higher education level may have superior ability to access and understand information and technology and may have been able to apply them more appropriately to their conditions than farmers with lower education. This result is in line with the finding of (Tiwari et al., 2008) and Elzo et al., 2010) Determinants of farmers' adoption of improved soil conservation technology in a middle mountain watershed of central Nepal.

Access to training (TRAIN): Access to training has been found to relate to the probability of participating in watershed management positively and significantly at $1 \%$ probability level as expected.This implies that, if women receive trainings, the probability of being participating in watershed management will also increase. This is because training of woman on watershed management issues make them aware of natural resource management.

A similar result was obtained in Kenya by Njiriri (2013) on women's role and participation in watershed management.

Access to credit (CREDIT): The result of the binary logit model show that women obtained credit has been found to be positively and significantly related to the probability of the participation watershed management at $5 \%$ probability level as expected. This implies that if women receive credit the probability of being participating in watershed management will increase. This is because credit facilitates the performance of watershed management activities.

Off farm income (INCOME): A negative relationship was found between participation and off farm income. In contrary to the priory hypothesized effect, this variable was found negative and significant at $1 \%$ probability level in influencing the probability of women's participation in watershed management. This may be due to the fact that the number of days' farmers work on an off farm job leaves them with little time for being associated with the watershed activities. Moreover, their dependence on watershed resources becomes less, leading to their disinterest in the programme. This result is in line with the finding (Amsalu and De Graaff, 2014) study determinants of adoption watershed management in an Ethiopian highland watershed found that, off farm income are the variables with significant negative influences. 


\section{SUMMARY, CONCLUSIONS AND RECOMMENDATIONS}

This chapter deals with summary, conclusions, recommendations and areas for future research

\subsection{Summary and Conclusions}

The study was initiated to investigate the factors affecting women participation in watershed management. Data were collected both from primary and secondary sources. The primary data was collected from a total 248 sample women's based on semi structured questionnaire. Secondary data were obtained from different sources like office of agriculture, women and children office, rural land administration office, environmental protection office of the Nono Benja district. Cross-section data that was collected from sample farmers and key informants was analyzed using descriptive statistics followed by econometric analysis. Results from descriptive statistics showed that the sample population differed significantly from each other in age, educational level, family size, credit service, training service, extension contact, off farm income, farm land and farm experience.

Average age of the respondent was 35 years while average education of respondents was grade 3 . Generally, it was agreed from the results of socio-economic and demographic characteristics in Nono Benja greatly affect women's participation in watershed management. The study established that socio-economic, demographic and institutional factors affect women's participation in watershed management both positively and negatively. Eighty percent of the respondents reported that though women were not the rightful owners of the land, accessibility was guaranteed especially for married men. This hinder them to participate on watershed management. survey results revealed that women participation in watershed management was very low. The reproductive role was found to be hinder women to participate in watershed management. In Gibe sub catchment, women due to their role of food, wood and water provision, they not actively involved watershed management. Challenging though, this factor has led to the low participation of women due to the need to sustain family needs.

On the other hand, 204 female respondents referred to reproductive role of women as a factor which limits their participation. The study found out from respondents $(81.9 \%)$ that low participation decisions on watershed management practices. This was attributed to their ever presence in the catchment and gender role of home management, food and water provision. Statistical result of socio-economic factors found that some factors were highly affecting women participation in decision making while others were not.

The results of the binary logit model are presented in Table 7. As it is indicated, age (AGE), education (EDUCLVL), training (TRAIN) and access to credit (CREDIT) were positively and significantly related to the probability of participation in watershed management, while off farm income (INCOME) was negatively and significantly related to the probability of women participation in watershed management.

Based on the objectives following conclusions were made: The existing socio-economic,demographic and institutional factors that affect women's participation in watershed management. Property ownership, accessibility and control which define who own what between women andmen not only affect decision making on such properties like land but also their implementationThe study concluded that reproductive role of women and ownership hinder them to participate in watershed management as they interact with it providing for household. Lack of property rights has completely hindered them from managing watershed resources. Itwas concluded thatother factors apart from socio-economic factors affect women's participation a great deal.Itwas observed that women located in extreme rural areas are disadvantaged in accessing information and skills being introduced in the catchment. They are hardly reached by extension agent and district technical staff. During discussion with KII and FGD, It seemed that women who lived in the further area show low participation. communication is not convenient, the information circulation is limited, especially in lower villages of the upper catchment. Women can not receive valid knowledge and appropriate practice.

Decision making for watershed management by women in Nono Benja district is not expressedboth at community and kebele levels. Women are not able to make decisions about watershed management practices since they are not always involved in meeting for watershed management. The study also concluded that integration of women in watershed management requires immediate rather than long term perspectives. This was derived from the approach provided by inovation flatform where women were given practical skills and amenities where they can participate willingly. These include providing them with training for their participationwhich has enticed many women to increase knowledge as well as their attitude in involvement in watershed management. Also created awareness and brought more women on field work and this encourages even more to participate in watershed management because they are interesting the ones already involved. On the contrary, some government programs which do not engage women lack community ownership and sustainability because women are not equipped with skills to manage them after the government has accomplished them. some physical structure in the catchment not functional, reason; they were constructed by the government without the involvement of all stakeholder local communities especially women and they cannot repair or maintain them. 


\subsection{Recommendations}

The study came up with the following recommendations which are vital in dealing with factors that affect women's participation in watershed management in Gibe sub-catchment of Nono Benja district.

$>$ As the role of women was affected by challenges of ownership of properties, a factor originating from inheritance culture, the study recommends the local government to promote a gender responsive land tenure system through locally made bylaws. This will improve their capacity to influence decisions and enhance their participation in watershed management.

$>$ The local government is expected to develop the skill, knowledge and capacity of women in relation to watershed management through capacity building.

$>$ Follow up mechanism should be initiated by district authorities and experts to show how gender relations have changed once a program has finished and what the impact has been on the watershed and the community as a whole.

$>$ Ministry of Agriculture should be a close and increased engagement of women as stakeholders and marshalling of political support at national, district, catchment and subsequently community levels. This will bridge the missing link between the national policies and plans to integrate women, institutional arrangement and cultural set up at the grass root.

$>$ Education had positive and significant effect on participation of women on watershed management in the study area. Therefore, policy makers/regional government should focus on the provision of adult education for women in the study area.

$>$ Training had positive and significant effect on participation of women in watershed management. Therefore, concerned body should focus on providing necessary training through development agents for women in the study area. Capacity building through training of beneficiaries is essential for creating awareness and involvement.

$>$ Off-farm income had negative and significant effect on women participation in watershed management activities. Therefore, policy makers should focus on how to create awareness on advantage and disadvantage of off-farm activities in relation to farm activities.

$>$ Credit had positive and significant effect on women participation in watershed management in the study area. Therefore, policy makers/concerned body should focus on providing appropriate credit services.

$>$ Policy and development emphasis on these factors would lead to greater participation of women in watershed management programme.

\section{Reference}

Ababa, A., 2014. Community based participatory sustainable land management byelaw formulation in the highlands of central ethiopia., 22(1), pp.9-20.

Adane, Y., 2010. Institute of development studies center for rural development studies integrated watershed development from sustainable livelihood.,(June).

Amsalu, A. and De Graaff, J., 2014. Determinants of adoption and continued use of stone terraces for soil and water conservation in an Ethiopian highland watershed. Ecological economics, 61(2), pp.294-302.

Anon, 2014. Case study Project to assist the Earthquake Reconstruction and Rehabilitation Authority ( ERRA ) and its partners in restoring livelihoods in the earthquake-affected areas of Pakistan.

Avitabile, V., Herold, M., Heuvelink, G., Lewis, S.L., Phillips, O.L., Asner, G.P., Armston, J., Ashton, P.S., Banin, L., Bayol, N.and Berry, N.J.,2016. An integrated pan - tropical biomass map using multiple reference datasets. Global change biology, 22(4), pp.1406-1420.

Rao,V.N.,2016. Empowerment of women for equitable Participation in watershed management for improved livelihoods and sustainable development: An Analytical Study., pp.1-20.

Samani, R.E. and Arayesh, M.B., 2015. Factors affecting women participation in preserving environment in Ilam City., 10(June), pp.99-104.

Sandhyarani, S. and Anup, D., 2013. Involvement of SHGs in watershed management - an impact analysis. Odisha Review, pp.49-52.

Schmidt, E. and Tadesse, F., 2015. Ensuring agricultural productivity over time: Impact of Sustainable Land Management Program on Rural Farmers in Ethiopia. , pp.1-26.

Seeley, J., 2010. Women's Participation in Watershed Development in India Women's Participation in Watershed Development in India Janet Seeley, Meenakshi Batra. , (January).

Smyle, Jim; Lobo, Chrispino; Milne, Grant; Williams, M., 2014. Watershed Development in India. An Approach Evolving through Experience.

Sreedevi, T.K., Wani, S.P. and Nageswara Rao, V., 2015. Empowerment of women for equitable participation in watershed management for improved livelihoods and sustainable development: an analytical study.

Svensson, L., 2014. Socio-economic Indicators for Causes and Consequences of Land Degradation. , pp.1-26. 
Tennyson, L., 2012. Review and Assessment of Watershed Management Strategies and Approaches. Proceedings of the Asian Regional Workshop on Watershed Management, pp.19-39.

Terefe, H.R., Asfaw, Z. and Demissew, S., 2015. Ecosystem \& Ecography The Link between Ethnobotany and Watershed Development for Sustainable Use of Land and Plant Resources in Ethiopia. , 5(2).

Tiwari, K.R., Sitaula, B.K., Nyborg, I.L. and Paudel, G.S., 2008. Determinants of farmers' adoption of improved soil conservation technology in a middle mountain watershed of central Nepal. Environmental management, 42(2), pp.210-222.

Wani, S.P. and Garg, K.K., 2016. 1.Watershed Management Concept and Principles.

Van der Zaag, P., 2005. Integrated Water Resources Management: Relevant concept or irrelevant buzzword? A capacity building and research agenda for Southern Africa. Physics and Chemistry of the Earth, Parts $A / B / C, 30(11)$, pp.867-871.

Wolancho, K.W., 2015. Evaluating watershed management activities of campaign work in Southern nations , nationalities and peoples ' regional state of Ethiopia.

Wolka, K., Moges, A. and Yimer, F., 2013. Farmers 'perception of the effects of soil and water conservation structures on crop production: The case of Bokole watershed, Southern Ethiopia. , 1(5), pp.71-80.

Worku, T. and Tripathi, S.K., 2015. Watershed Management in Highlands of Ethiopia :

Https://www.researchgate.net/publication/237696769_Participatory_Watershed_Managem $n t \_$__Case_Study_of_Salaiyur_Watershed_in_Coimbatore_India

\section{APPENDICES}

Appendix I: VIF for continuous variables

\begin{tabular}{lll}
\hline Variable & VIF & 1/VIF \\
\hline AGR & 1.19 & 0.841297 \\
FARM & 1.15 & 0.866871 \\
ELR & 1.05 & 0.953476 \\
FSFR & 1.04 & 0.962701 \\
LNDSZE & 1.03 & 0.970298 \\
\hline Mean VIF & 1.09 & \\
\hline
\end{tabular}

Appendix II: Contingency Coefficient (CC) for dummy variables

\begin{tabular}{lllll} 
& TSOR NOECR & CSOR & OFIR \\
\hline TSOR & 1 & & & \\
NOECR & -0.0315 & 1.0000 & 1 & \\
CSOR & 0.0364 & 0.0215 & 0.2193 & 1 \\
OFIR & 0.1073 & -0.2263 & & \\
\hline
\end{tabular}

